\title{
Koefisien debit pintu crump de gruyter dan pintu sorong (studi kasus pada BF 3 dan BF 4 BPU 15 daerah irigasi Punggur Utara)
}

\author{
Della Andandaningrum a, Endro Prasetyo Wahono b, ${ }^{\text {, }}$, Dyah Indriana Kusumastutic \\ ${ }^{a}$ Mahasiswa Magister Teknik Sipil, Universitas Lampung, Jl. Soemantri Brojonegoro No. 1 Bandar Lampung, 35145, Indonesia \\ ${ }^{b}$ Jurusan Teknik Sipil, Universitas Lampung, Jl. Soemantri Brojonegoro No. 1 Bandar Lampung, 35145, Indonesia \\ c Jurusan Teknik Sipil, Universitas Lampung, Jl. Soemantri Brojonegoro No. 1 Bandar Lampung, 35145, Indonesia
}

\section{H I G H L I G H T S}

- Perhitungan debit dan koefisien debit pada pintu BF-3 dan BF-4 telah dilakukan

- Kehikangan air di pintu BF-3 dn BF-4 bervariasi bahkan sampai 18\% menunjukkan banyak hambatan terjadi di saluran seperti pencurian air, sampah, kerusakan saluran, serta rumput liar.

\section{N F O A R T I K E L}

Riwayat artikel:

Diterima 19 Januari 2021

Diterima setelah diperbaiki 15 Februari 2021

Diterima untuk diterbitkan 15 Maret 2021

Tersedia secara online 01 April 2021

\section{Kata kunci:}

Crump de gryter,

debit,

koefisien debit,

pintu sorong

\section{A B S T R A K}

Koefisien debit $(C d)$ didefinisikan sebagai perbandingan antara debit nyata dan debit teoritis. Pada DI Punggur Utara BPU 15, permasalahan pada sistem irigasi terjadi karena beberapa faktor, salah satunya adalah kondisi pintu yang perlu dievaluasi. Tujuan dari penelitian ini adalah untuk menganalisis koefisien debit pintu tipe crump de gruyter dan pintu sorong pada pintu BF 3 dan BF 4 sebagai fungsi bukaan pintu air dan menganalisis kinerja pintu sebagai pengatur debit. Penelitian ini dilakukan dengan mengidentifikasi debit pintu dan kondisi pintu serta menghitung koefisien debitnya. Hasil analisis menunjukkan bahwa debit yang dihasilkan berbeda. Untuk pintu BF 3 debit yang dihasilkan antara $0,1028 \mathrm{~m}^{3} / \mathrm{s}$ sampai dengan $0,6417 \mathrm{~m}^{3} / \mathrm{s}$ dengan $C d$ rata-rata sebesar 0,8559 sedangkan untuk pintu BF 4 debit yang dihasilkan antara $0,0296 \mathrm{~m}^{3} / \mathrm{s}$ sampai dengan $0,6361 \mathrm{~m}^{3} / \mathrm{s}$ dengan $C d$ rata-rata 0,82313. Dan untuk kinerja pintu antara $\mathrm{BF} 3$ dan BF 4 terdapat selisih kehilangan air sebesar $0,0006 \mathrm{~m}^{3} / \mathrm{s} \mathrm{sampai} 0,0276 \mathrm{~m}^{3} / \mathrm{s}$.

Diterbitkan oleh Jurusan Teknik Sipil Universitas Lampung

\section{Pendahuluan}

Daerah irigasi (DI) Punggur Utara merupakan bagian dari daerah irigasi Sekampung Sistem, dengan tipe irigasi teknis dan memiliki luas fungsional 31,296 Ha dari luas areal baku yaitu sebesar 41,925 Ha. Daerah irigasi Punggur Utara ini memiliki beberapa permasalahan pada sistem irigasi yang ada, yaitu air yang dialirkan tidak sampai ke petak sawah terakhir. Hal itu terjadi karena faktor pembagian air dan faktor kehilangan air di sepanjang saluran irigasi menuju petak sawah. Padahal pengelolaan sawah petani sangat memerlukan air untuk dapat mengelola tanah yang keras agar dapat menjadi lumpur. Sehubungan dengan kondisi di atas, penelitian ini sangatlah penting dilakukan untuk mengetahui pengelolaan air irigasi

\footnotetext{
* Penulis koresponden. Alamat e-mail: epwahono@eng.unila.ac.id (E.P. Wahono). Peer review dibawah tanggung-jawab Jurusan Teknik Sipil Universitas Lampung. https://doi.org/10.23960/rekrjits.v25i1.15
}

tersebut sehingga diharapkan dapat membantu mengatasi permasalahan yang dihadapi oleh para petani di DI Punggur Utara ini. Penelitian ini dilakukan di DI Punggur Utara dikarenakan masyarakatnya merupakan penghasil padi, kondisi pintu yang masih dapat dipergunakan dengan baik dan pembagian air yang pada saat dilakukan penelitian, pembagian air masuk ke DI BPU 15. Distribusi aliran di saluran ini merata dan tidak ada aliran memutar, aliran tidak terganggu sampah, tanaman air dan bangunan air lainnya. Tujuan dari penelitian ini adalah untuk menganalisis koefisien debit jenis pintu crump de gruyter dan pintu sorong pada pintu BF 3 dan $\mathrm{BF} 4$ daerah irigasi Punggur Utara, dan kinerja pintu saluran sekunder BF 3 dan $\mathrm{BF} 4$ sebagai pengatur atau regulator debit.

\section{Tinjauan Pustaka}

Irigasi adalah usaha untuk memperoleh air yang menggunakan bangunan dan saluran buatan untuk keperluan produksi pertanian [1]. Istilah irigasi diartikan suatu bidang pembinaan atas air dari sumber-sumber air termasuk kekayaan alam hewani yang terkandung di 
dalamnya, baik yang alamiah maupun yang diusahakan manusia. Pengairan selanjutnya diartikan sebagai pemanfaatan serta pengaturan air dan sumber-sumber air yang meliputi irigasi, pengembangan daerah rawa, pengendalian banjir, serta usaha perbaikan sungai, waduk dan pengaturan penyediaan air minum, air perkotaan dan air industri [2].

Selanjutnya, debit (discharge) atau besarnya aliran saluran adalah volume aliran yang mengalir melalui suatu penampang melintang saluran per satuan waktu. Biasanya dinyatakan dalam satuan $\mathrm{m}^{3} /$ detik atau liter/detik. Rumus umum yang biasa digunakan adalah Persamaan (1).

$$
Q=\sum(A x V)
$$

dengan $\mathrm{Q}$ adalah debit (m3/detik), A adalah luas bagian penampang basah saluran (m2) dan $\mathrm{V}$ adalah kecepatan aliran rata-rata pada luas bagian penampang basah saluran (m/detik). Sedangkan koefisien debit $\left(C_{d}\right)$ adalah perbandingan antara debit nyata dan debit teoritis. Nilai koefisien debit tergantung pada nilai $C_{v}$ dan $C_{c}$, seperti Persamaan (2) yang nilai reratanya adalah 0,62 [3].

$$
C d=C_{v} \times C_{c}
$$

dengan $C d$ adalah koefisien debit, $C V$ adalah koefisien kecepatan dan $C c$ adalah koefisien kontraksi.

Pintu sorong ini termasuk dalam pintu pembilas bawah, yang mempunyai beberapa keunggulan antara lain tinggi muka air hulu dapat dikontrol dengan tepat, struktur kuat dan sederhana, serta sedimen yang diangkut oleh saluran hulu dapat melewati pintu bilas. Selain beberapa keunggulan tersebut, ada beberapa kelemahan dalam pelaksanaan operasi jaringan irigasi, yaitu kebanyakan benda-benda hanyut dapat tersangkut di pintu, dan yang paling utama kehilangan energi di hilir cukup besar [4]. Rumus debit yang dapat dipakai untuk pintu sorong adalah Persamaan (3).

$$
Q=K \mu a b \sqrt{2 g h_{1}}
$$

dengan $\mathrm{Q}$ adalah debit $\left(\mathrm{m}^{3} / \mathrm{s}\right), \mathrm{K}$ adalah faktor aliran tenggelam, $\mu$ adalah koefisien debit, a adalah bukaan pintu (m), b adalah lebar pintu (m), g adalah percepatan gravitasi $\left(\mathrm{m} / \mathrm{s}^{2}\right)(9,81)$ dan $\mathrm{h}_{1}$ adalah kedalaman air di depan pintu di atas ambang $(\mathrm{m})$.

Selanjutnya, alat ukur crump de gruyter adalah saluran ukur leher panjang yang dipasangi pintu gerak vertikal yang searah aliran (streamline). Kelebihan bangunan ini dapat mengukur dan mengatur sekaligus, tidak mempunyai masalah dengan sedimen, eksplotasi mudah dan pengukuran teliti, dan merupakan bangunan kuat. Kelemahan bangunan ini adalah pembuatannya rumit dan mahal, biaya pemeliharaan mahal, kehilangan tinggi energi besar, serta bangunan ini mempunyai masalah dengan benda-benda hanyut [5]. Berikut Persamaan (4) adalah rumus debit untuk alat ukur crump de gruyter sesuai dengan perencanaan hidrolis.

$$
Q=C d b w \sqrt{\left(2 g\left(h_{1}\right)-w\right)}
$$

dengan $\mathrm{Q}$ adalah debit $\left(\mathrm{m}^{3} / \mathrm{s}\right)$, Cd adalah koefisien debit $(0,94), \mathrm{b}$ adalah lebar bukaan $(\mathrm{m}), \mathrm{w}$ adalah bukaan pintu (m) $(\mathrm{w}<0,63 \mathrm{~h} 1)$, g adalah percepatan gravitasi $\left(\mathrm{m} / \mathrm{s}^{2}\right)$ $(9,81)$ dan $\mathrm{h}_{1}$ adalah kedalaman air di depan pintu di atas ambang (m). Sedangkan efisiensi pengaliran (drainage efficiency) yakni efisiensi di saluran utama primer dan sekunder dari bendung sampai ke sadap tersier, dan dapat dihitung dengan Persamaan (5) [6].

$$
E_{f}=\frac{\text { debit inflow }- \text { debit outflow }}{\text { debit outflow }} \times 100 \%
$$

\section{Metode Penelitian}

Penelitian ini dilakukan pada dua tempat yaitu Laboratorium Hidrolika Universitas Lampung dan daerah irigasi Punggur Utara BPU 15 Kecamatan Punggur Utara, Kabupaten Lampung Tengah yaitu di Pintu BF 3 dan Bf 4 . Lokasi pengukuran terletak di Daerah Irigasi Punggur Utara terletak pada koordinat $105^{\circ} 13^{\prime} \mathrm{BT}-105^{\circ} 17^{\prime} \mathrm{BT}$ dan 457' LS - 4²59' LS BPU 15, Pintu BF 3 dan BF 4. Pengukuran dilakukan selama 4 hari dari tanggal 1 Oktober 2018 sampai dengan 4 Oktober 2018 yang dilakukan mulai pukul 07.00 wib sampai dengan 17.00 wib.Alat yang digunakan untuk pengukuran di lapangan adalah current meter dengan baling-baling. Proses pengukuran pada kedua jenis pintu BF 3 dan BF 4 dilakukan pada setiap simulasi bukaan pintu dengan tinggi $2 \mathrm{~cm}, 4 \mathrm{~cm}, 6 \mathrm{~cm}, 8 \mathrm{~cm}, 10 \mathrm{~cm}, 12 \mathrm{~cm}$ dan seterusnya sampai dengan bukaan $40 \mathrm{~cm}$ dengan debit tetap. Pengukuran debit dilakukan pada saat kondisi air sudah di sekitar pintu sudah tenang. Survei pendahuluan dilakukan untuk menentukan pintu mana yang akan dipilih sebagai titik lokasi penelitian dan mengamati keadaan daerah serta kondisi lokasi penelitian. Survei lapangan dilakukan untuk medapatkan data primer dengan cara melakukan pengukuran langsung menggunakan alat current meter. Data sekunder berupa data curah hujan dan klimatologi tahun 2018 yang bersumber dari Stasiun Meteorologi Radin Inten II. Setelah semua data terkumpul langkah selanjutnya adalah menganalisis koefisien debit teoritis jenis pintu crump de gruyter dan pintu sorong pada skala laboratorium, menganalisis koefisien debit pada pintu BF 3 dan $\mathrm{BF} 4$ daerah irigasi punggur utara serta menganalisis kinerja pintu di saluran sekunder BF 3 dan BF 4 sebagai pengatur atau regulator debit.

\section{Hasil dan Pembahasan}

\subsection{Perhitungan debit saluran BF 3 dan BF 4}

Nilai debit yang diperoleh dari setiap titik percobaan kemudian dijumlah dan dirata - ratakan. Setelah itu nilai debit dikumulatif menjadi sebuah nilai debit yang ditentukan untuk titik tersebut. Tinjauan perhitungan untuk debit aliran pintu saluran, tinjauan juga dilakukan terhadap grafik hubungan antara besarnya debit yang dihasilkan terhadap tinggi bukaan pintu.

Berdasarkan hasil perhitungan pada Tabel 1 menunjukkan bahwa dari hasil penelitian yang dilakukan pada pintu BF 3, debit hasil pengukuran yang didapatkan bervariasi yaitu dari debit terkecil pada bukaan pintu 0,02 m dengan nilai $0,151 \mathrm{~m}^{3} / \mathrm{s}$ - dan debit terbesar dihasilkan pada bukaan pintu $0,4 \mathrm{~m}$ dengan nilai $0,642 \mathrm{~m}^{3} / \mathrm{s}$. Dan rata - rata debit yang dihasilkasn pada pintu BF 3 adalah 0,414 $\mathrm{m}^{3} / \mathrm{s}$. Dilihat dari bukaan pintu $0,02 \mathrm{~m}-0,4 \mathrm{~m}$ terlihat bahwa semakin besar bukaan pintu, maka semakin besar jumlah debit yang dikeluarkan.

Dari hasil perhitungan di Tabel 2 menunjukkan bahwa debit hasil pengukuran yang didapatkan bervariasi yaitu dari debit terkecil pada bukaan pintu 0,02 $\mathrm{m}$ dengan nilai 
$0,030 \mathrm{~m}^{3} / \mathrm{s}$ - dan debit terbesar dihasilkan pada bukaan pintu $0,4 \mathrm{~m}$ dengan nilai $0,636 \mathrm{~m}^{3} / \mathrm{s}$. Pada bukaan pintu $0,34 \mathrm{~m}$ dan $0,36 \mathrm{~m}$ debit yang dihasilkan tidak berubah yaitu $0,576 \mathrm{~m}^{3} / \mathrm{s}$. Dan rata - rata debit yang dihasilkan pada pintu BF 4 adalah $0,402 \mathrm{~m}^{3} / \mathrm{s}$. Elevasi yang dihasilkan pada pintu BF 4 ini bervariasi, tetapi pada beberapa bukaan pintu terdapat elevasi yang sama yaitu bukaan pintu $0,02 \mathrm{~m}-0,08 \mathrm{~m}$ dengan elevasi $0,69 \mathrm{~m}$ sedangkan $0,14 \mathrm{~m}-0,22 \mathrm{~m}$ dengan elevasi $0,73 \mathrm{~m}$. Walaupun ada beberapa elevasi yang sama pada setiap bukaan pintu, debit yang dihasikan tetap berbeda. Oleh karena itu dilihat dari bukaan pintu 0,02 $\mathrm{m}-0,4 \mathrm{~m}$ terlihat bahwa semakin besar bukaan pintu, maka semakin besar jumlah debit yang dikeluarkan.

Tabel 1

Debit hasil pengukuran pintu BF 3

\begin{tabular}{llll}
\hline No & $\begin{array}{l}\text { Bukaan } \\
\text { pintu }(\mathrm{m})\end{array}$ & $\begin{array}{l}\text { Debit } \\
\left(\mathrm{m}^{3} / \mathrm{s}\right)\end{array}$ & $\begin{array}{l}\text { Elevasi } \\
(\mathrm{m})\end{array}$ \\
\hline 1 & 0 & 0,103 & 0,27 \\
2 & 0,02 & 0,151 & 0,32 \\
3 & 0,04 & 0,179 & 0,35 \\
4 & 0,06 & 0,229 & 0,38 \\
5 & 0,08 & 0,286 & 0,44 \\
6 & 0,1 & 0,310 & 0,45 \\
7 & 0,12 & 0,312 & 0,47 \\
8 & 0,14 & 0,338 & 0,51 \\
9 & 0,16 & 0,379 & 0,53 \\
10 & 0,18 & 0,410 & 0,55 \\
11 & 0,2 & 0,442 & 0,56 \\
12 & 0,22 & 0,450 & 0,57 \\
13 & 0,24 & 0,487 & 0,61 \\
14 & 0,26 & 0,513 & 0,62 \\
15 & 0,28 & 0,531 & 0,63 \\
16 & 0,3 & 0,555 & 0,64 \\
17 & 0,32 & 0,569 & 0,66 \\
18 & 0,34 & 0,592 & 0,675 \\
19 & 0,36 & 0,592 & 0,685 \\
20 & 0,38 & 0,621 & 0,695 \\
21 & 0,4 & 0,642 & 0,705 \\
\hline
\end{tabular}

Tabel 2

Debit hasil pengukuran pintu BF 4

\begin{tabular}{llll}
\hline No & $\begin{array}{l}\text { Bukaan } \\
\text { pintu }(\mathrm{m})\end{array}$ & $\begin{array}{l}\text { Debit } \\
\left(\mathrm{m}^{3} / \mathrm{s}\right)\end{array}$ & $\begin{array}{l}\text { Elevasi } \\
(\mathrm{m})\end{array}$ \\
\hline 1 & 0 & 0,0296 & 0,58 \\
2 & 0,02 & 0,1298 & 0,69 \\
3 & 0,04 & 0,1516 & 0,69 \\
4 & 0,06 & 0,2283 & 0,69 \\
5 & 0,08 & 0,2819 & 0,69 \\
6 & 0,1 & 0,3098 & 0,72 \\
7 & 0,12 & 0,3105 & 0,72 \\
8 & 0,14 & 0,3366 & 0,73 \\
9 & 0,16 & 0,3775 & 0,73 \\
10 & 0,18 & 0,4072 & 0,73 \\
11 & 0,2 & 0,4322 & 0,73 \\
12 & 0,22 & 0,4436 & 0,73 \\
13 & 0,24 & 0,4845 & 0,76 \\
14 & 0,26 & 0,4907 & 0,75 \\
15 & 0,28 & 0,5265 & 0,77 \\
16 & 0,3 & 0,5483 & 0,77 \\
17 & 0,32 & 0,5614 & 0,81 \\
18 & 0,34 & 0,5760 & 0,795 \\
19 & 0,36 & 0,5760 & 0,8 \\
20 & 0,38 & 0,6071 & 0,805 \\
21 & 0,4 & 0,6361 & 0,825 \\
\hline
\end{tabular}

\subsection{Koefisien debit BF 3 dan BF 4}

Berdasarkan pengukuran pintu BF 3 di lapangan di dapatkan hasil yang disajikan pada Tabel 3.

Tabel 3

Analisis koefisien debit pintu BF 3

\begin{tabular}{lllllll}
\hline No & $\begin{array}{l}\text { Bukaan } \\
\text { Pintu }(\mathrm{m})\end{array}$ & $\begin{array}{l}\text { Debit } \\
\left(\mathrm{m}^{3} / \mathrm{s}\right)\end{array}$ & $\begin{array}{c}\text { Elevasi } \\
(\mathrm{m})\end{array}$ & $\begin{array}{c}\text { Lebar } \\
\text { Pintu }\end{array}$ & $\begin{array}{c}\left((2 . \mathrm{g} \cdot(\mathrm{h}))^{\wedge} 0,5\right. \\
C d\end{array}$ \\
\hline 1 & 0 & 0,1028 & 0,27 & 0,85 & 2,3004 & 0 \\
2 & 0,02 & 0,1512 & 0,32 & 0,85 & 2,4249 & 3,6667 \\
3 & 0,04 & 0,1792 & 0,35 & 0,85 & 2,4650 & 2,1381 \\
4 & 0,06 & 0,2290 & 0,38 & 0,85 & 2,5044 & 1,7932 \\
5 & 0,08 & 0,2857 & 0,44 & 0,85 & 2,6563 & 1,5817 \\
6 & 0,1 & 0,3104 & 0,45 & 0,85 & 2,6192 & 1,3943 \\
7 & 0,12 & 0,3122 & 0,47 & 0,85 & 2,6192 & 1,1687 \\
8 & 0,14 & 0,3384 & 0,51 & 0,85 & 2,6930 & 1,0559 \\
9 & 0,16 & 0,3791 & 0,53 & 0,85 & 2,6930 & 1,0352 \\
10 & 0,18 & 0,4097 & 0,55 & 0,85 & 2,6930 & 0,9944 \\
11 & 0,2 & 0,4418 & 0,56 & 0,85 & 2,6563 & 0,9785 \\
12 & 0,22 & 0,4500 & 0,57 & 0,85 & 2,6192 & 0,9188 \\
13 & 0,24 & 0,4875 & 0,61 & 0,85 & 2,6930 & 0,8874 \\
14 & 0,26 & 0,5133 & 0,62 & 0,85 & 2,6563 & 0,8744 \\
15 & 0,28 & 0,5308 & 0,63 & 0,85 & 2,6192 & 0,8515 \\
16 & 0,3 & 0,5550 & 0,64 & 0,85 & 2,5815 & 0,8431 \\
17 & 0,32 & 0,5687 & 0,66 & 0,85 & 2,5815 & 0,8100 \\
18 & 0,34 & 0,5924 & 0,675 & 0,85 & 2,5624 & 0,8000 \\
19 & 0,36 & 0,5922 & 0,685 & 0,85 & 2,5239 & 0,7668 \\
20 & 0,38 & 0,6208 & 0,695 & 0,85 & 2,4848 & 0,7736 \\
21 & 0,4 & 0,6417 & 0,705 & 0,85 & 2,4450 & 0,7720 \\
\hline \multicolumn{7}{c}{$C d$ rata-rata } \\
\hline
\end{tabular}

Berdasarkan hasil perhitungan debit yang dihasilkan berbeda - beda pula yaitu dari bukaan pintu 0,02 $\mathrm{m}$ dengan debit $0,1028 \mathrm{~m}^{3} / \mathrm{s}$ sampai dengan bukaan pintu $0,4 \mathrm{~m}$ dengan debit $0,6417 \mathrm{~m}^{3} / \mathrm{s}$. Pada Tabel $3 C d$ yang dihasilkan bervariasi yaitu pada bukaan pintu 0,02 m Cd yang dihasilkan sebesar 3,6667 - dan pada bukaan pintu 0,4 m $C d$ yang dihasilkan 0,7720 . Dimana menghasilkan $C d$ ratarata sebesar 0,8559. Dari hasil koefisien debit yang dihasilkan antara bukaan pintu 0,18 m - 0,4 m nilai koefisien debitnya sesuai dengan nilai yang disarakan pada standar perencanaan KP-04 (Direktorat Irigasi dan Rawa). Sedangkan pada bukaan pintu 0,02 $\mathrm{m}$ - 0,16 m nilai koefisien debit yang dihasilkan tidak sesuai dengan standar yang disarankan di KP-04 yang berarti pada bukaan pintu tersebut ada indikasi kebocoran pintu. Dan semakin besar bukaan pintu makan semakin kecil koefisien debit yang dihasilkan.

Pengukuran pintu BF 4 di lapangan diperoleh hasil koefisien debit yang disajikan pada Tabel 4. Berdasarkan hasil perhitungan debit yang dihasilkan berbeda - beda pula yaitu dari bukaan pintu $0,02 \mathrm{~m}$ dengan debit 0,0296 $\mathrm{m}^{3} / \mathrm{s}$ sampai dengan bukaan pintu $0,4 \mathrm{~m}$ dengan debit $0,6361 \mathrm{~m}^{3} / \mathrm{s}$. Pada Tabel $4 C_{d}$ yang dihasilkan bervariasi yaitu pada bukaan pintu $0,02 \mathrm{~m} C_{d}$ yang dihasilkan sebesar 2,387366 - dan pada bukaan pintu 0,4 m $C_{d}$ yang dihasilkan 0,73466. Dimana menghasilkan $C_{d}$ rata-rata sebesar 0,82313. Dari hasil koefisien debit yang dihasilkan antara bukaan pintu $0,14 \mathrm{~m}-0,4 \mathrm{~m}$ nilai koefisien debitnya sesuai dengan nilai yang disarakan pada standar perencanaan KP-04 (Direktorat Irigasi dan Rawa).

Dari hasil perhitungan di laboratorium dan di lapangan dapat disimpulkan bahwa kedua data dan hasil perhitungan yang ada sangat jauh berbeda. Hal ini dapat terjadi dikarenakan pada skala laboratorium tidak dilakukan nya pemodelan sama seperti pintu yang ada di lapangan. Dan dalam hal ini yang ingin dilihat adalah 
bagaimana fenomena koefisien debit pintu crump de gruyter dan pintu sorong baik di lapangan maupun di laboratorium. Dari berbagai bukaan pintu dan dengan debit yang dihasilkan sehingga memunculkan persamaan yang ada, maka persamaan-persamaan tersebut diatas dapat digunakan untuk regulator debit dengan muka air di hulu yang konstan.

Tabel 4

Analisis koefisien debit pintu BF 4

\begin{tabular}{|c|c|c|c|c|c|c|}
\hline No & $\begin{array}{l}\text { Bukaan } \\
\text { Pintu (m) }\end{array}$ & $\begin{array}{l}\text { Debit } \\
\left(\mathrm{m}^{3} / \mathrm{s}\right)\end{array}$ & $\begin{array}{l}\text { Elevasi } \\
\text { (m) }\end{array}$ & $\begin{array}{l}\text { Lebar } \\
\text { pintu }\end{array}$ & $\begin{array}{l}\text { ((2.g.(h- } \\
\text { a) })^{\wedge} 0,5\end{array}$ & $C d$ \\
\hline 1 & 0 & 0,0296 & 0,58 & 0,75 & 3,3716 & 0 \\
\hline 2 & 0,02 & 0,1298 & 0,69 & 0,75 & 3,6238 & 2,387 \\
\hline 3 & 0,04 & 0,1516 & 0,69 & 0,75 & 3,5693 & 1,416 \\
\hline 4 & 0,06 & 0,2283 & 0,69 & 0,75 & 3,5140 & 1,443 \\
\hline 5 & 0,08 & 0,2819 & 0,69 & 0,75 & 3,4577 & 1,358 \\
\hline 6 & 0,1 & 0,3098 & 0,72 & 0,75 & 3,4860 & 1,184 \\
\hline 7 & 0,12 & 0,3105 & 0,72 & 0,75 & 3,4293 & 1,006 \\
\hline 8 & 0,14 & 0,3366 & 0,73 & 0,75 & 3,4006 & 0,942 \\
\hline 9 & 0,16 & 0,3775 & 0,73 & 0,75 & 3,3425 & 0,941 \\
\hline 10 & 0,18 & 0,4072 & 0,73 & 0,75 & 3,2833 & 0,918 \\
\hline 11 & 0,2 & 0,4322 & 0,73 & 0,75 & 3,2230 & 0,893 \\
\hline 12 & 0,22 & 0,4436 & 0,73 & 0,75 & 3,1616 & 0,850 \\
\hline 13 & 0,24 & 0,4845 & 0,76 & 0,75 & 3,1925 & 0,843 \\
\hline 14 & 0,26 & 0,4907 & 0,75 & 0,75 & 3,0990 & 0,812 \\
\hline 15 & 0,28 & 0,5265 & 0,77 & 0,75 & 3,0990 & 0,809 \\
\hline 16 & 0,3 & 0,5483 & 0,77 & 0,75 & 3,0351 & 0,802 \\
\hline 17 & 0,32 & 0,5614 & 0,81 & 0,75 & 3,0990 & 0,754 \\
\hline 18 & 0,34 & 0,5760 & 0,795 & 0,75 & 2,9863 & 0,756 \\
\hline 19 & 0,36 & 0,5760 & 0,8 & 0,75 & 2,9367 & 0,726 \\
\hline 20 & 0,38 & 0,6071 & 0,805 & 0,75 & 2,8862 & 0,738 \\
\hline 21 & 0,4 & 0,6361 & 0,825 & 0,75 & 2,8862 & 0,734 \\
\hline \multicolumn{6}{|c|}{ Cd rata-rata } & 0,823 \\
\hline
\end{tabular}

\subsection{Analisis kinerja pintu air metode kehilangan air}

Dari hasil pengukuran kecepatan aliran yang telah dilakukan diperoleh nilai debit yang berbeda-beda pada setiap bukaan pintu nya. Hasil yang diperoleh dari perhitungan tersebut menunjukkan semakin tinggi bukaan pintu, maka debit yang dihasilkan semakin besar. Tabel 5 menunjukkan hasil perhitungan selisih antara debit ratarata pengukuran pada pintu BF3 dan BF4.

Tabel 5

Selisih pengukuran debit pintu BF 3 dan BF 4

\begin{tabular}{llllll}
\hline No & $\begin{array}{l}\text { Bukaan } \\
\text { Pintu } \\
(\mathrm{m})\end{array}$ & $\begin{array}{l}\text { Debit } \\
\mathrm{BF} 3 \\
\left(\mathrm{~m}^{3} / \mathrm{s}\right)\end{array}$ & $\begin{array}{l}\text { Debit } \\
\mathrm{BF} 4 \\
\left(\mathrm{~m}^{3} / \mathrm{s}\right)\end{array}$ & $\begin{array}{l}\text { Kehilangan } \\
\left(\mathrm{m}^{3} / \mathrm{s}\right)\end{array}$ & $\begin{array}{l}\text { Persen } \\
\text { hilang } \\
(\%)\end{array}$ \\
\hline 1 & 0,02 & 0,1512 & 0,1298 & 0,0214 & 16,48 \\
2 & 0,04 & 0,1792 & 0,1516 & 0,0276 & 18,17 \\
3 & 0,06 & 0,2290 & 0,2283 & 0,0007 & 0,31 \\
4 & 0,08 & 0,2857 & 0,2819 & 0,0038 & 1,33 \\
5 & 0,1 & 0,3104 & 0,3098 & 0,0006 & 0,20 \\
6 & 0,12 & 0,3122 & 0,3105 & 0,0017 & 0,54 \\
7 & 0,14 & 0,3384 & 0,3366 & 0,0018 & 0,54 \\
8 & 0,16 & 0,3791 & 0,3775 & 0,0016 & 0,43 \\
9 & 0,18 & 0,4097 & 0,4072 & 0,0026 & 0,63 \\
10 & 0,2 & 0,4418 & 0,4322 & 0,0097 & 2,24 \\
11 & 0,22 & 0,4500 & 0,4436 & 0,0064 & 1,45 \\
12 & 0,24 & 0,4875 & 0,4845 & 0,0030 & 0,61 \\
13 & 0,26 & 0,5133 & 0,4907 & 0,0226 & 4,61 \\
14 & 0,28 & 0,5308 & 0,5265 & 0,0043 & 0,81 \\
15 & 0,3 & 0,5550 & 0,5483 & 0,0067 & 1,22 \\
16 & 0,32 & 0,5687 & 0,5614 & 0,0074 & 1,31 \\
17 & 0,34 & 0,5924 & 0,5760 & 0,0165 & 2,86 \\
18 & 0,36 & 0,5922 & 0,5760 & 0,0162 & 2,82 \\
19 & 0,38 & 0,6208 & 0,6071 & 0,0137 & 2,26 \\
20 & 0,4 & 0,6417 & 0,6361 & 0,0056 & 0,88 \\
\hline \multicolumn{2}{l}{ Rata-rata } & 0,4295 & 0,4208 & 0,0087 & 2,99 \\
\hline
\end{tabular}

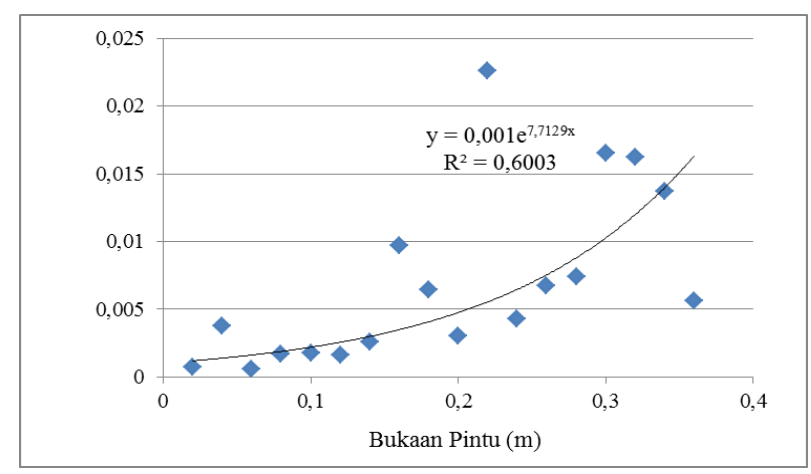

Gambar 5 Grafik selisih pengukuran debit BF 3 dan BF 4

Tabel 5 menunjukkan hasil pengukuran debit yang keluar dari pintu BF 3 berbeda dengan hasil pengukuran dari pintu BF 4. Dimana kehilangan air atau presentase kehilangan airnya berbeda dan tidak stabil pada setiap bukaan pintu nya. Selisih pengukuran bervariasi yaitu kehilangan air terkecil berada di bukaan pintu $0,10 \mathrm{~m}$ dengan kehilangan air sebesar $0,20 \%$ atau $0,0006 \mathrm{~m}^{3} / \mathrm{s}$ dan yang terbesar ada pada bukaan pintu 0,04 m dengan kehilangan air $18,17 \%$ atau $0,0276 \mathrm{~m}^{3} / \mathrm{s}$. Berdasarkan Standar perencanaan irigasi pada kriteria perencanaan (KP 03) menyebutkan bahwa pada umumnya kehilangan air di jaringan irigasi sekunder berkisar antara 5\% - 10\%. Dengan demikian nilai ini sudah di atas batas wajar kehilangan yang umum terjadi di saluran sekunder yaitu lebih dari $10 \%$, yang artinya kondisi saluran sepanjang BF 3 dan BF 4 banyak terjadi hambatan yang dimungkinkan seperti pencurian air, sampah-sampah sepanjang saluran, kerusakan lining saluran, atau tidak adanya lining, serta rumput- rumput liar yang berada di sepanjang saluran.

\section{Simpulan}

Simpulan yang diperoleh dari hasil penelitian adalah sebagai berikut:

1. Hasil perhitungan data lapangan menunjukkan bahwa koefisien debit yang dihasilkan pada pintu BF 3 berkisar antara $0,1028 \mathrm{~m}^{3} / \mathrm{s}-0,6417 \mathrm{~m}^{3} / \mathrm{s}$ dengan $C_{d}$ rata-rata 0,8559 . Sedangkan koefisien debit yang dihasilkan pada pintu BF 4 berkisar antara $0,0296 \mathrm{~m}^{3} / \mathrm{s}-0,6361 \mathrm{~m}^{3} / \mathrm{s}$ dengan $C_{d}$ rata-rata 0,82313 . Hal ini menunjukkan bahwa semakin besar debit yang dihasilkan maka semakin kecil nilai koefisien debit nya.

2. Dari hasil pengamatan dan perhitungan dapat dilihat bahwa kinerja pintu di saluran sekunder BF 3 dan BF 4 masih berfungsi dengan baik. Namun dilihat dari metode kehilangan air didapat selisih pengukuran yaitu $0,0006 \mathrm{~m}^{3} / \mathrm{s}$ sampai dengan $0,0276 \mathrm{~m}^{3} / \mathrm{s}$. Jika dihitung presentasinya yaitu berkisar antara $0,20 \%$ sampai dengan 18,17\%. Hasil ini diluar Standar perencanaan irigasi pada kriteria perencanaan (KP 03) yang menyebutkan bahwa pada umumnya kehilangan air di jaringan irigasi sekunder berkisar antara $5 \%-10 \%$.

\section{Daftar Pustaka}

[1] Kurnia: Hemat air irigasi - kebijakan, teknik, pengelolaan dan sosial budaya, Pusat Dinamika Pembangunan Universitas Padjajaran. Bandung. 1997 
[2] Ambler, J.S.: Irigasi di Indonesia - dinamika kelembagaan petani. LP3ES. Jakarta, 1991

[3] Triatmodjo, B.: Hidrolika II. Penerbit Beta Offset, Yogyakarta, 1996

[4] Binilang, A.: Perilaku hubungan antar parameter hidrolis air loncat melalui pintu sorong pada saluran terbuka, 4(1), 2014, 41-44.

[5] KP 09 Kementrian Pekerjaan Umum - Dirjen Sumber Daya Air: Standar perencanaan irigasi, kriteria perencanaan bagian standar pintu pengatur air irigasi. 2013

[6] Ray, K., Linsley, Jr., Kohler, M.A., Paulhus, J.L.H.: Hidrologi untuk insinyur - edisi ketiga. Jakarta. Penerbit Erlangga, 1996 